\title{
La gobernanza local
}

\author{
Juan-Cruz Alli Aranguren \\ Profesor Titular de Derecho Administrativo \\ Universidad Pública de Navarra
}

SUMARIO: I. LA GOBERNANZA. CONCEPTO Y SIGNIFICADO. II. LA GOBERNANZA ECONÓMICA LIBERAL. III. LA GOBERNANZA EN UN ENTORNO COMPLEJO. 1. La complejidad normativa. 2. La complejidad organizativa y la descentralización. 3. El sistema competencial. 4. La gobernanza europea. IV. LA GOBERNANZA LOCAL. 1. Concepto y características. 2. Se fundamenta en las relaciones de cooperación. 3. Democracia y participación. 4. La gobernanza y la creación de redes. V. CONCLUSIÓN.

\section{LA GOBERNANZA. CONCEPTO Y SIGNIFICADO}

El Diccionario de la Lengua define gobernanza como el «arte o manera de gobernar que se propone como objetivo el logro de un desarrollo económico, social e institucional duradero, promoviendo un sano equilibrio entre el Estado, la sociedad civil y el mercado de la economía» ${ }^{1}$. Se ha dado un nuevo concepto a un antiguo término cuyo significado era equivalente a gobernación como «acción o efecto de gobernar o gobernarse» ${ }^{2}$. Se amplió definiendo un modelo de gobierno en sus fines y relaciones políticas, sociales y económicas, articulado con la sociedad civil y el mercado. Introduce la idea de que «los asuntos políticos son el centro de integración de todos los elementos analíticos del sistema social y no uno de dichos elementos específicos» ${ }^{3}$.

En el cambio de significados del concepto asoma un aspecto ideológico de origen neoliberal que lo convierte en «esencialmente controvertible» con un uso axiológico evaluador de un modo de ejercicio del poder ${ }^{4}$. El nuevo significado en el contenido del término acredita que tiene «no solamente una función denotativa o descriptiva, sino también persuasiva y

\footnotetext{
${ }^{1}$ Real Academia Española, Diccionario de la lengua española, 22 $2^{a}$ edición, Espasa, Madrid, 2001.

${ }^{2}$ Real Academia Española, Diccionario de la lengua española, $21^{\text {a }}$ edición, Rivadeneyra, Madrid, 1992. Sobre la relación entre conceptos y términos, Q. SKINNER, Los fundamentos del pensamiento político moderno, I, México, 1985, p. 8.

${ }^{3}$ T. PArsons, The Social System, The Free Press, Glencoe, III, 1951, p. 126.

${ }^{4}$ N. Boвbio, Estado, sociedad y gobierno, FCE, México, 1990, concreta el uso de un término en el sistemático, el histórico y el axiológico.
} 
normativa», por cuanto el debate sobre la gobernanza «está especialmente abierto a, y depende de, la tensión entre hechos y valores» ${ }^{5}$.

La gobernanza referida a los modos de acción administrativa en un orden neoliberal, en el que se reduce el protagonismo de los poderes públicos y se trata de integrar a la sociedad, ha sido definida como «un proceso de coordinación de actores, grupos sociales e instituciones para atender fines propios discutidos y definidos colectivamente en medios fragmentados e inciertos» 6 . También como «las nuevas formas interactivas de gobierno en las cuales los actores privados, las diferentes organizaciones públicas, los grupos o comunidades de ciudadanos, y otros tipos de actores, participan en la formulación de la acción política, que se estructura en un sistema de redes» ${ }^{7}$.

La Commission on Global Governance creada en 1992 por iniciativa de Willy Brandt definió la gobernanza como «la suma de diferentes modos en que los individuos y las instituciones, públicos y privados, gestionan los asuntos comunes. Es un proceso continuo de cooperación y acomodación entre intereses diversos y conflictivos. Incluye a las instituciones oficiales y a las dotadas con poderes ejecutivos, así como los acuerdos informales sobre los que los pueblos y las instituciones se ponen de acuerdo o que prevén serán de su interés» ${ }^{8}$.

El concepto de gobernanza y las definiciones anteriores revelan que se trata de un modo de gobernar caracterizado por

a) Superar la exclusividad de la gestión de los asuntos públicos por parte de los poderes públicos dotados de potestades exorbitantes y de una capacidad coercitiva sobre la sociedad. Esta concepción se apoya en la crisis del Estado social y en su ejercicio exclusivo del

\footnotetext{
${ }^{5}$ G. SARTori, Teoría de la democracia, I, Alianza, México, 1989, p. 27.

${ }^{6}$ A. BaGnasco, P. Le Galès, «Les villes européennes comme société et comme acteur», Villes en Europe, Le Découverte, Paris, 1997, p. 38.

${ }^{7}$ G. Marcou, F. Rangeon, J.-L. Thiebault, «Les relations contractuelles entre collectivités publiques», Le gouvernement des villes. Territoire et pouvoir, Descartes \& Cie, 1997, p. 140. P. CALAME, A. Talmant, L'État au coeur. Le Meccano de la gouvernance, Desclée de Brouwer, París, 1997, sostienen que por gobernanza se ha de entender la capacidad de las sociedades para dotarse de sistemas de representación, instituciones, procesos y organización para gestionar por sí mismas y de modo armónico los tres tipos de sistemas complejos: los ecológicos, los socio-culturales y los técnicos.

${ }^{8}$ Commission on Global Governance, Our Global Neighbourhood, Oxford, 1995. M. Smouts, «Du bon usage de la gouvernance en relations internationales», La Gouvernance, Revue internationales des sciences sociales (RISS), 155, 1998, p. 88. C. HewitT de AlCÁNTARA, «Du bon usage du concept de gouvernance», RISS, 155, 1998, pp. 109-118.
} 
poder, como nueva aportación a la superación del modelo anterior y de las dificultades que para el mismo se han derivado de una nueva realidad económica ${ }^{9}$.

b) Reconocer la pluralidad de agentes sociales con posibilidad de intervenir en los asuntos públicos e interdependencia entre ellos, de modo que implique su participación y cooperación en la toma de decisiones, en la gestión, en la evaluación y en las responsabilidades.

c) Configurar redes intergubernamentales e interadministrativas por la cooperación, en las que se elaboran y ejecutan las políticas públicas con la colaboración de organizaciones gubernamentales y agentes sociales ${ }^{10}$.

\section{LA GOBERNANZA ECONÓMICA NEOLIBERAL}

En el actual concepto de gobernanza se observa una clara influencia de la concepción neoliberal, que rechaza el Estado de bienestar y reduce la actividad de los poderes públicos ${ }^{11}$. Uno de los epígonos de la Escuela de Chicago, Ronald COASE, estudió la reducción y supresión de los costes de transacción en las empresas. Fue en relación con ellas como se empezó a hablar de corporate governance o gobernance structures, como técnicas para lograr la desaparición de los costes de transacción por medio de protocolos de trabajo, usos de normas, asociaciones temporales, etc., con la voluntad de incrementar el beneficio.

Esta teoría y práctica empresariales fueron trasladadas por la escuela neoinstitucionalista a las relaciones jurídicas, sociales y políticas, para valorarlas en términos de rentabilidad y eficiencia económica ${ }^{12}$. Para ello

\footnotetext{
${ }^{9}$ F.-X. MERRIEN, «De la gouvernance des États-providences contemporains», RISS, 155, 1998, pp. 61-71, arguye cómo el funcionalismo no permite realizar un análisis correcto de la evolución del Estado social, y que las propuestas de la gobernanza son simplistas y valoran incorrectamente la aportación normativa e institucional de los Estados.

${ }^{10} \mathrm{P}$. LE GALÈs, «Du gouvernement des villes à la gouvernance urbaine», Science politque, 45, 1, pp. 57-95, asimila la gobernanza a las «interacciones entre el Estado y la sociedad y a los modos de coordinación para hacer posible la actividad pública». Sobre los diversos conceptos del sintagma políticas públicas, A. Fernández, «Las políticas públicas», en M. CAminal BadíA, Manual de Ciencia Política, Madrid, 1999, p. 464.

${ }^{11}$ La cuestión fue analizada por la Comisión Trilateral, H. SKLAR, The Trilateral Comisión and Elite Planning for Word Management, South Presss, Boston, 1980, pp. 1-2.

12 Para Olivier Williamson, la gobernanza son los dispositivos puestos en práctica por la empresa para conseguir una coordinación eficaz por medio de protocolos internos cuando está integrada y
} 
se trata de reducir o suprimir los costes de la gestión pública externalizándolos y poniéndolos en manos del sector privado y de la sociedad civil, que los producen a menores costes, con lo que se logra reducir el gasto público y aumentar el beneficio privado. Ésta es la lógica económica de los procesos de privatización de empresas públicas, de externalización de actividades administrativas y de transformación de servicios públicos en actividades privadas de interés general. En este sentido se entiende como buena gobernanza la puesta en manos del sector privado, al que se denomina sociedad civil, sean empresas u Organizaciones No Gubernamentales, la gestión de servicios públicos ${ }^{13}$.

La privatización y externalización, que forman parte de la crisis del Estado Social, se inició con los servicios públicos locales durante el gobierno de Margaret Thatcher, quien redujo sustancialmente los recursos públicos destinados al gasto social. Ha pasado a formar parte de la realidad del poder y la Administración actuales. Esta visión economicista ha contribuido a la reducción del gasto público, pero también ha afectado a las funciones públicas y ha suprimido espacios de participación ciudadana en la gestión pública. Desde esa perspectiva se debieran reducir los costes de transacción que se derivan de la actividad pública, de modo que se estableciese un sistema de «gobierno sin gobierno» ${ }^{14}$, en el que el interés público estuviese sustituido por la rentabilidad o eficiencia económicas gestionado desde la sociedad civil.

Las actitudes antiglobalización han criticado la gobernanza porque establece un nuevo orden político en el que la democracia representativa parlamentaria, en la que el ciudadano es protagonista de la soberanía popular y la expresión de su voluntad y del interés general, se sustituye por un «gobierno de las organizaciones, por las organizaciones y para las orga-

jerarquizada o por contratos, patrocinio o uso de normas cuando se relaciona con subcontratistas. Citado por D. LoRRAIN, «Administrer, gouverner, réguler», Gouvernances, Les Anales de la recherche urbaine, 80-81, 1998, p. 85.

${ }^{13}$ Se ha defendido la aplicación de la regla al interior de las empresas capitalistas, lo que parcialmente se ha logrado con la cogestión y las empresas de la economía social. J. STigLitz, «Participation and Development. Perspectives from the Comprehensive Development Paradigm», Remarks at the International Conference on Democracy, Mark Economy and Development, The World Bank Group, Seul, 27 de febrero de 1999, p. 4: «muchas de las emisiones de ideas [...] (participación/gobernanza) son relevantes no sólo para los gobiernos, sino también para la gobernanza de las corporaciones. Las corporaciones son instituciones públicas: reúnen fondos de lo «público» y los emplean en capitales productivos; dadas las imperfecciones en la movilidad laboral, un trabajador que está maltratado o despedido no puede tornar a otras opciones gratuitamente».

${ }^{14}$ W. H. ReINICKE, Global Public Policy, Governing without Government?, Washington, 1998. 
nizaciones» ${ }^{15}$, que representan a porciones sociales y a intereses particulares: «La gran paradoja de la gobernanza es que se nos propone ampliar la democracia hacia la sociedad civil, que es precisamente aquel conjunto de relaciones en que no soy ciudadano, sino mero agente de un interés particular. Sólo soy ciudadano como integrante del pueblo soberano. Las prerrogativas que colocan la ley, expresión de la voluntad del soberano, por encima del interés privado son la única garantía de los ciudadanos que integran la persona colectiva del soberano contra la desigualdad y contra la dominación de los más débiles por los más fuertes. [...] Su proyecto de devolución del poder a la sociedad civil significa la desaparición misma del espacio público de participación política ciudadana que queda sustituido por el espacio privado del mercado y de la sociedad civil. Los arreglos privados en el seno de la sociedad civil pasarán a sustituir el principio de legalidad [...] De hecho, en este particular esquema, el Estado no expresa ningún interés general debiéndose arbitrar entre los intereses particulares, con lo cual sólo representa el interés particularísimo de sus burocracias» ${ }^{16}$.

Este análisis no refleja la realidad por cuanto la presencia de la sociedad en la toma de decisiones ha estado siempre viva, al menos desde que se superó el individualismo liberal y se reconoció que el ciudadano forma parte de una comunidad política, que existe como realidad social vertebrada por sus propias organizaciones, a su vez manifestación de uno de los derechos individuales más importantes. Por otra parte, la globalización no puede verse sólo desde una perspectiva económica, sin considerar que «la acción efectiva en respuesta a las transformaciones globales debe basarse en razonamientos que tengan en cuenta la moral, la equidad global y la consecución de una vida digna. El concepto de raison d'humanité debe ser el sustituto constructivo de la raison d'état: expresa la idea de que la humanidad tiene necesidades y aspiraciones que la gobernanza en todos sus niveles debería favorecer como una de sus tareas principales y establecer imperativos morales categóricos que vinculen cualquier forma de gobernación. Deben considerarse aspectos de la gobernanza tales como las nociones de derechos humanos, responsabilidades, pluralismo cultural o solidaridad» ${ }^{17}$.

\footnotetext{
${ }^{15}$ S. Anderson, T. Burns, «The European Union and the Erosion of Parliamentary Democracy. A Study of Post-Parliamentary Governance in the European Union», How democratic is it?, London, 1996, p. 229.

16 J. Brown, De la Gobernanza o la constitución de la política del neoliberalismo, http://www.attac.org.

${ }^{17}$ Y. Dror, La capacidad de gobernar. Informe al Club de Roma, FCE, México, 1994, cap. IX.
} 


\section{LA GOBERNANZA EN UN ENTORNO COMPLEJO}

Hay complejidad cuando resultan inseparables los elementos que constituyen un todo, que exige comprender la unidad en la diversidad y la diversidad en la unidad. La complejidad parte de la presencia de numerosos actores públicos y privados con objetivos y valores diferentes y aun contradictorios, con diferentes ámbitos de poder político, administrativo, económico y social, pluralidad de competencias territoriales y funcionales, medios económico-financieros y jurídicos. Existe diversidad de vínculos y relaciones entre los actores, fundados en móviles, intereses, afinidad, alianza, oposición, neutralidad o indiferencia. La complejidad se manifiesta en diversos modos de organización, participación y presencia en los procesos de decisión y ejecución, que configuran redes.

Asimismo, la complejidad se caracteriza porque la evolución desorganiza los sistemas reorganizándolos, por no ser lineal, por existir cambios, turbulencias, reacciones y comportamientos imprevistos o que, siendo previsibles, no se puedan controlar sin profundas variaciones. En un sistema complejo la estrategia no aísla al actor de la organización, sino que le obliga a buscar en ella la racionalidad y a comprenderla, por lo que debe prevalecer sobre el programa: «El programa establece una secuencia de acciones que deben ser ejecutadas sin variación en un medio estable, pero cuando hay modificación de las condiciones exteriores el programa queda bloqueado. La estrategia, por el contrario, elabora un escenario de acción [...] que privilegia tanto la prudencia como la audacia y, si es posible, ambas [...] la estrategia puede y debe efectuar compromisos a menudo» ${ }^{18}$.

La gobernanza reconoce que la complejidad exige superar el simplismo y asumir el conjunto complejo como único modo de tratar los problemas particulares que sólo pueden ser valorados en su contexto, siguiendo la regla comprender para poder actuar. De tal modo que el conocimiento integral constituye un elemento necesario para la acción. Una estructura compleja y activa produce los elementos y efectos necesarios para su propia existencia y organización por medio de las paradojas que existen entre «variedad-unidad», «autonomía-dependencia» y «receptividad-eficiencia» ${ }^{19}$.

La paradoja «variedad-unidad» plantea la cuestión de cómo atender, tratar y resolver la diversidad y complejidad del sistema respetando e integrando su unidad, de tal modo que el todo pueda desarrollarse y mantener

\footnotetext{
${ }^{18}$ E. Morin, Les sept savoirs nécessaires à l'éducation du futur, Éditions du Seuil, París, 2000, pp. 39,59 y 100 .

${ }^{19}$ E. Morin, La méthode. La nature de la nature, I, Éditions du Seuil, París, 1977, p. 186.
} 
su propia entidad, a pesar de la transformación de las partes. Se trata de asumir sin ruptura de la unidad las tensiones verticales y horizontales que, con diverso contenido material, se han de producir e incidan en la potenciación del concepto de unidad o, por el contrario, en la transformación y pérdida de aquella, porque las soluciones resulten incoherentes con el mínimo de unidad y cohesión que se articule en las acciones políticas. La consideración sistémica permite tratar los distintos elementos que integran el entorno complejo dotados de fines u objetivos que ejercen una actividad y evolucionan sin perder su identidad.

La paradoja «autonomía-dependencia» contrapone la capacidad de decisión reconocida a un sujeto público o privado con la limitación derivada de la necesidad de garantizar el todo, de modo que aquella se ha de desarrollar dentro de los elementos que garanticen la realidad en la que la autonomía se desarrolla. Tal es el caso de las acciones parciales respecto al marco superior en que se integran.

La paradoja «receptividad-eficacia y eficiencia» se establece entre la recepción de las aportaciones de la participación democrática en los procesos de decisión, propia de un Estado social y democrático, y la eficaciaeficiencia de las decisiones. Se persigue obtener la máxima eficacia - alcanzar los objetivos - y eficiencia - hacerlo con el menor costopara evitar el despilfarro de los recursos.

La complejidad que trata de organizar la gobernanza se refiere a los órdenes normativo, organizativo y competencial ${ }^{20}$.

\section{La complejidad normativa}

A partir de la mundialización económica y la información globales se ha producido un cambio de paradigma respecto a la capacidad normativa del Estado, como la fuente más importante del Derecho y autor de un orden jurídico unificado y jerarquizado. En el orden formal se ha alterado el sistema de fuentes, y en el sustantivo se han incorporado contenidos normativos y estándares externos, que producen cambios notables en el Derecho estatal $^{21}$, transformando los sistemas jurídico-estatales por nuevas normas y estándares que los armonizan y homogeneízan.

\footnotetext{
${ }^{20}$ J.-B. Auby, «La bataille de San Romano. Réflexions sur les évolutions récentes du droit administratif», AJDA, 11, 2001, pp. 916-921.

21 J.-B. Auby, «La bataille...», cit., p. 913. S. RiAls, Le juge administratif française et la technique du standard (essai sur le traitement juridique de l'idée de normalité), Paris, LGDJ, 1980.
} 
Desde las organizaciones internacionales se establecen reglas e instituciones que se aplican a actividades al margen del territorio en que se desarrollen, que constituyen un Derecho internacional de las actividades económicas. Normas que afectan a las relaciones entre los Estados, aunque en una economía globalizada tienen como destinatarios inmediatos a las organizaciones subestatales, a las empresas y a los individuos en condiciones de competencia. La internacionalización del Derecho sobre la contratación pública establecida por la Organización Mundial del Comercio, las fórmulas propuestas por el Banco Mundial y el Fondo Monetario Internacional y la normativa y políticas comunitarias manifiestan la erosión del poder estatal y su limitada capacidad en la materia ${ }^{22}$.

Además, desde instituciones internacionales, sean o no de origen estatal, se está configurando un Derecho convencional, válido en cuanto a las adhesiones que suscita, porque no tiene el carácter unilateral e imperativo ni capacidad de imposición propias del Derecho estatal. No se reconoce a sus normas un poder normativo intrínseco derivado de su autoridad, sino de su aceptación y de la adhesión a sus mandatos por los sujetos destinatarios, que constituyen nuevas formas de «gobernanza orgánica»: «Frente a la creciente complejidad y dinamismo [...] están emergiendo nuevas formas de regulación y gobernanza. A escala sectorial nos encontramos con diversas redes o comunidades estables que intervienen en políticas, subgobiernos y gobiernos de intereses privados que incluyen grupos de interés implicados en cuestiones o problemas relacionados con aspectos de políticas particulares o sectoriales» ${ }^{23}$. Esta situación la previó DUGUIT: «a mi juicio es un gran error creer que el progreso social se mide por medio de las nuevas leyes que dictan los gobernantes. Por otra parte, en el porvenir, [...] harán cada vez menos leyes, porque las relaciones de los individuos y los grupos se regirán sobre todo por regulaciones convencionales [...] por la regulación que resulte de un acuerdo entre dos o más grupos,

M. Hauriou, «Police juridique et fond du droit», Aux sources du droit. Le pouvoir, l'ordre et la liberté, Blound \& Gay, Paris, 1933, pp. 150-151, distinguió en el common law entre la regla de Derecho y el standard, que es un procedimiento «destinado a guiar al juez o al administrador, en la administración, dejándole un cierto poder discrecional [...] el estándar es un elemento de método, comparable a ese instrumento que permite al comandante de una nave calcular un punto en longitud y latitud. Después decidirá la ruta a seguir. La ruta a seguir es la directiva, pero para lograrla es preciso tener el punto, saber dónde se está, cuáles son los datos de la situación».

22 Ch. FouAssier, «Vers un véritable droit communautaire des concessions?», RTDE, octobredécembre 2000, pp. 675 y ss.

23 T. Burns, The Future of Parliamentary Democracy: Transition and Callenge in European Governance, Green Paper Prepared for the Conference of the Speakers of EU Parliaments, Rome, 22-24 september, 2000, sectión III, cap. 4. 
los gobernantes no deberán intervenir más que para darle la sanción, controlarlo y vigilarlo» ${ }^{24}$.

En este sentido pueden servir de ejemplo la Convención Internacional de mercaderías de Viena de 1980, los «Principios relativos a los contratos del comercio internacional» de Roma de 1994 elaborados por el Instituto Internacional para la unificación del Derecho privado (UNIDROIT), las leyes-tipo de la Comisión de las Naciones Unidas para el Derecho del Comercio Internacional (CNUDCI) o las normas ISO sobre normalización industrial ${ }^{25}$.

No se descarta la posibilidad de que pueda existir un reconocimiento oficial de determinados acuerdos hasta convertirlos en parte del ordenamiento jurídico, como es notorio en el caso de los derivados de «diálogo social» entre sindicatos y organizaciones patronales y de acuerdos que pueden ser incorporados al Derecho comunitario europeo ${ }^{26}$.

DELmas-MARTY ${ }^{27}$ ha aludido al riesgo de una «catástrofe normativa», en el sentido de la teoría de los sistemas jurídicos, por el cambio de escala y la ruptura producida por articulaciones cada vez más complejas e interactivas que producen perturbaciones en la fase de transición de uno a otro modelo normativo, que en el futuro será totalmente diferente del tradicional. Los actuales desafíos al quehacer jurídico se producen por cuanto existe una pluralidad de procesos de internacionalización del Derecho

\footnotetext{
${ }^{24}$ L. Dugurt, Le droit social, le droit individuel et la transformation de l'État, París.1908, p. 57.

${ }^{25}$ Los trabajos más importantes en la materia fueron elaborados por la Federación Internacional de Asociaciones Nacionales de Normalización (ISA) creada en 1926. La actual Organización Internacional de Normalización (ISO) se creó el 23 de febrero de 1947 y dictó su primera norma en 1951, sobre la «temperatura normal de referencia de las medidas industriales de longitud». De entre las dictadas destacan las Normas ISO 14000 y 14001 sobre gestión del medio ambiente. Existen en Europa un Comité Europeo de Normalización (CEN) y un Instituto Europeo de Normas de Telecomunicaciones (ETSI), responsables del desarrollo y adopción de las normas EN, HD y ENV, con un mandato de la Comisión conforme a la Directiva 98/48/CE, del Parlamento y del Consejo, de 20 de julio de 1998, por la que se establece un procedimiento de información en materia de las normas y reglamentaciones técnicas y de las reglas relativas a los servicios de la sociedad de la información. La Directiva 98/34/CE creó un Comité de normas y reglamentaciones técnicas y de las reglas relativas a los servicios de la sociedad de la información.
}

${ }^{26}$ Libro Blanco sobre la Gobernanza Europea. Profundizar en la democracia de la Unión Europea, Programa de trabajo, Documento de trabajo de los servicios de la Comisión, 11-10-2000, SEC (200), 1747/7, p. 16. P. MAGNETtE, E. RemaCle, Le nouveau modèle européen, I, Institutions et gouvernance, Bruselas, 2.000.

${ }^{27}$ M. Delmas-Marty, «Les processus de mondialisation du droit», Revue Politique et Parlementaire, 1015, nov.-déc. 2001, pp. 81-91; «La mondialisation du droit: chances et risques», Recueil Dalloz, 1999, $5^{\circ}$ cahier, pp. 10-15. 
que producen confusión en un espacio que es normativamente policéntrico, en el que coexisten normas de escala internacional, nacional y regional. Los conjuntos normativos organizados en diferentes escalas producen una integración que desde el Derecho nacional conduce al regional y al internacional.

El orden jurídico camina hacia muy distintas opciones y retos de unificación, uniformidad o armonización. La unificación implica hacer un todo de cosas distintas que se reducen a una misma especie por la existencia de las mismas reglas en un sistema jurídico único ${ }^{28}$. La uniformidad implica dar las mismas reglas a sistemas jurídicos distintos. La armonización evita la discordancia o el rechazo entre dos o más partes de un todo, o dos o más cosas que deben concurrir a un mismo fin. Se trata de aproximar sistemas jurídicos diferentes por medio de reglas que los hagan compatibles por disponer de reglas y principios comunes en un umbral de compatibilidad.

El nuevo orden produce una ruptura epistemológica respecto al pensamiento jurídico dominante caracterizado por una concepción jerarquizada y unificada del orden jurídico. La ruptura no hace desaparecer el orden unificado, sino que lo combina con el que se deriva de la pertenencia a un conjunto con un contenido de referencia, de modo que se produce la pertenencia a órdenes normativos diferentes y no jerarquizados. Se configura un orden jurídico más complejo con uno mundial superpuesto a los nacionales: «En estas condiciones, el Derecho estatal no puede ser concebido conforme al modelo nacional, incluso federal o confederal, sino como un modelo que se puede denominar de pluralismo ordenado: pluralismo por responder al riesgo de hegemonía; ordenado para evitar a la vez la fragmentación y la incoherencia, organizando el pluralismo en torno de nociones comunes» ${ }^{29}$.

La complejidad del Derecho es la expresión jurídica de la complejidad intrínseca de la realidad económica, social y técnica, a la que pretende atender y darle la regulación pertinente. Esta regulación no resulta factible desde una causalidad lineal y mecánica, sino que, como ciencia social, ha de considerar que «donde aumenta el número y la variedad de los subsistemas sociales, crece la autonomía de sus códigos y se engrosan las redes de interconexión e interdependencia funcionales de los diversos subsiste-

\footnotetext{
${ }^{28}$ En la Unión Europea se ha propuesto la unificación de normas penales para la protección de los intereses financieros contra los fraudes al presupuesto comunitario en un espacio judicial dotado de reglas de procedimiento y unidad de interpretación por el Tribunal e Justicia, que configuraría un corpus iuris penal y procesal.
}

${ }^{29}$ M. Delmas-Marty, «La mondialisation...», cit., p. 13. 
mas», [de modo que los integrantes] «de la relación potestativa detentan alguna porción de poder, y ningún detentador lo puede ejercer eficazmente sin considerar que incluso el último, el más débil destinatario de la relación potestativa, conserva alguna capacidad reflexiva para ejercer poder, influencia o autoridad» ${ }^{30}$.

La evolución expuesta conduce a pensar que los órdenes internacional y europeo seguirán influyendo decisivamente en la configuración de un sistema de fuentes plural, formalmente distinto y sustancialmente adaptado a los nuevos contenidos. La futura existencia de una Constitución europea y de un claro sistema de derechos y de normas supondrá la aportación de un nuevo marco para la mayor unificación de los Derechos nacionales.

\section{La complejidad organizativa y la descentralización}

La organización se ha hecho más compleja y desjerarquizada por la existencia de los niveles internacionales, regionales supraestatales, estatales, regionales infraestatales y locales, en un sistema que no se fundamenta en las relaciones verticales de jerarquía como en el pasado, sino en las horizontales de cooperación. Para AuBy, la globalización económica determina que ciertos marcos territoriales sean más pertinentes que otros: «son las regiones, cuyos tamaños les permiten la oportunidad de desarrollar estrategias internacionales, y las grandes áreas metropolitanas, en las cuales tienden a concentrarse de manera creciente las actividades económicas. Sin duda, no es por causalidad que sea sobre estos dos niveles de organización local donde se concentran los esfuerzos de reflexión y de reforma, tanto en Francia como en la mayoría de Estados comparables» ${ }^{31}$.

El Estado ya no controla todas las relaciones, porque la existencia de un nivel de autonomía las hace posibles entre los distintos niveles integrando redes de cooperación territorial. Esto resulta cada vez más evidente en el espacio regional europeo que ha asumido la existencia de los gobiernos regionales y la cooperación entre ellos configurando «eurorregiones» con sus acuerdos de cooperación entre regiones de distintos Estados, incluso con la creación de órganos comunes.

Tanto la globalización como el neoliberalismo reducen el poder social y económico del Estado y la Administración en beneficio de la autonomía individual y del mercado, con la modificación de las estructuras adminis-

\footnotetext{
${ }^{30}$ D. Zolo, La democracia difícil, Alianza, México, 1994, pp. 40-41.

31 J.-B. Auby, «Globalización y descentralización», RAP, 156, 2001, p. 19.
} 
trativas, estatuto y relaciones jurídicas, y con su descentralización funcional y territorial. Se han utilizado nuevos medios para estar presente en la actividad socio-económica, como los organismos autónomos, las empresas públicas, las sociedades de economía mixta, las sociedades mercantiles. A veces se ha desfigurado la diferenciación entre órganos públicos y sujetos privados, así como las atribuciones propias de las personas jurídicas públicas con las aportaciones económicas y el régimen de las empresas privadas, cuya titularidad y gestión controla, a las que ha encomendado partes de su actividad.

La relación entre el interés público y el privado en las nuevas estructuras orgánicas condiciona el régimen jurídico por la tendencia a ampliar el ámbito de lo privado a costa de lo público. Las normas que potencian el mercado y los agentes económicos promueven los procesos de privatización de empresas públicas, de externalización de actividades administrativas y de transformación de servicios públicos en actividades privadas de interés general, aun cuando resulte difícil aclarar su naturaleza pública o privada ${ }^{32}$. Se observa, también, la progresiva utilización del Derecho privado y de las relaciones contractuales, de la reducción de las acciones dotadas de imperium y del predominio de los fines e intereses subjetivos en las relaciones jurídico-administrativas ${ }^{33}$.

Constata Auby cómo la globalización afecta a las sociedades nacionales y a las instituciones estatales desde el exterior, mientras que la descentralización lo hace desde el interior. Ambos procesos actúan simultáneamente, de modo que globalización y descentralización resultan paralelas: «Entre la globalización y la descentralización existe una familiaridad innata. No sólo constituyen dos fuerzas de tensión contra las que nuestros aparatos públicos están conjuntamente sometidas, sino que de alguna manera están unidas la una a la otra. Al impulsar las realidades y los mecanismos transnacionales, la globalización encuentra [...] las estructuras territoriales, que, por el contrario, ven en ella un vector de emancipación [...] el Estado se encuentra en medio de un bocadillo [...] [hay que] pensar en una visión y una práctica diferentes de la soberanía, dado que [...] en el mundo que se forma la soberanía es menos una barrera territorialmente definida que un recurso de comercio para una política caracterizada por unas redes transnacionales complejas» ${ }^{34}$.

\footnotetext{
32 J. ToRnos Mas, «Derecho Público y Derecho Privado en la regulación administrativa», en Giornate di studio in onore di M. S. Giannini, Giuffrè, Bologna, 1997, p. 179.

${ }^{33}$ E. García de EnTerría, Problemas del derecho público al comienzo del siglo, Madrid, Civitas, 2000.

34 J.-B. Auby, «Globalización...», cit., pp. 20-21.
} 
El proceso de descentralización interna del poder político reduce el estatal en beneficio de las entidades locales, a las que se reconoce autonomía en la Carta Europea del Consejo de Europa de 1985, y de nuevas unidades políticas o administrativas dentro de los Estados. Tomemos como ejemplo los Estados federales y regionales, y la transformación de Estados centralistas en Estados descentralizados de tipo autonómico como el caso de España en la que se reconoce la autonomía y los hechos diferenciales de las nacionales y regiones que la integran ${ }^{35}$.

La descentralización plantea una nueva forma de separación de poderes de carácter vertical que produce un aumento de los centros de decisión, una mayor complejidad institucional y una colaboración necesaria en la articulación de las funciones y relaciones entre los poderes territoriales para poder ejercer las competencias en cada uno de los niveles del poder.

Las tendencias económicas y sociales de la posmodernidad aportan una nueva lógica a los Estados y a sus Administraciones e invalidan los medios tradicionales de actuar de los poderes públicos. Todo ello está produciendo una transformación del contenido del Derecho administrativo para su adaptación a los profundos cambios socio-económicos que atribuyen un nuevo papel al Estado y a la Administración, con una menor presencia del poder en la vida social ${ }^{36}$.

\section{El sistema competencial}

El régimen competencial está directamente afectado por la presencia de ámbitos de decisión supra e infraestatales, por la pérdida de poder de intervención y por el mayor protagonismo social en la toma de decisiones político-administrativas por el aumento de las redes de cooperación y la participación interadministrativa e intersocial propias de la gobernanza.

\footnotetext{
35 J.-P. DuвoIs, «Une révolution silencieuse: vers une nouvelle séparation des pouvoirs», Esprit, janvier, 2002, pp. 122-135, expone la mutación silenciosa de la Constitución de la V República que produce la descentralización sobre el dogma de la unidad y la indivisibilidad de la República, que reserva al nivel nacional el monopolio de la representación política y el poder legislativo, y refleja el centralismo de las leyes de 10 de agosto de 1871 y 5 de abril de 1884: «Estamos en una fase de transición llena de ambigüedades y contradicciones: la parte esencial de la distribución vertical de las competencias, tan fundamental como la horizontal, no está determinada por la Constitución sino por un conjunto de tratados europeos y de leyes descentralizadoras que han modificado progresivamente, en cuanto a la territorialización del poder, la real naturaleza del régimen político francés».

${ }^{36}$ S. CASSESE, «Crisis y transformaciones del Derecho Administrativo», DA, 250-251, 1998, pp. 215-225.
} 
El estatuto jurídico de la intervención pública se fundamentaba en el interés general y en las prerrogativas administrativas, a partir del reconocimiento del liderazgo de la Administración como ordenadora de la vida social y económica en el Estado y en la Economía social de mercado. El cambio del paradigma y el paso a un modelo distinto, en el que, conforme a la libertad de comercio e industria, se atribuye mayor protagonismo a los agentes económicos y al mercado, en detrimento del poder estatal y administrativo, ha sometido a discusión los fundamentos y régimen de la actividad administrativa. Sin embargo, ante el necesario protagonismo del Estado y la Administración, reconocido incluso desde el neoliberalismo, es oportuno recordar la valoración que realizó el politólogo Danilo ZoLo: «la autonomía de los individuos y de los grupos sociales intermedios está tan protegida en los sistemas políticos modernos que es necesario pensar cómo tutelar las prerrogativas del poder para ponerlo en grado de desarrollar su función decisional, con lo cual contrasta el pluralismo de los vetos cruzados que surgen de un ambiente social complejo, vuelto intratable por una sobrecarga de interdependencias funcionales» ${ }^{37}$.

La gobernanza ha establecido que el servicio público, como concepto que amparaba la acción, haya dado paso a atribuir un mayor significado a las actividades de policía y de fomento. La propia categoría se ha visto reducida en su alcance por el predominio en el Derecho comunitario de los conceptos de libertad de comercio e industria, libre concurrencia y circulación de personas y bienes, así como por la utilización de categorías distintas y más garantes de la igualdad, como las de «servicio de interés económico general» o de «servicio universal». También ha afectado a la contratación y a la externalización de servicios y actividades antes ejecutadas directamente por la Administración y los agentes administrativos.

En una sociedad democrática y participativa, cada día más orientada a la economía de mercado y libre concurrencia, pierden peso el poder administrativo y sus decisiones unilaterales, aun cuando no se cuestione el fundamento teórico del acto administrativo como producto típico de la actividad y poder administrativos. Se mantiene el acto, pero se va modificando el método para su producción a través de la participación y de la incorporación en el procedimiento administrativo de la voluntad individual y colectiva, del acceso a la información y datos, de la presencia de órganos consultivo-participativos, de trámites de información pública, etc. Se ha asumido la existencia de actos consensuados o transaccionales en su producción, aun cuando reciban la forma final de acto administrativo típico.

${ }^{37}$ D. Zolo, La democracia..., cit., p. 89. 
También aquí se introducen la regulación y los principios del Derecho comunitario sobre la materia y la doctrina de los Tribunales de Justicia y de Derechos humanos.

En los actos bilaterales de la contratación administrativa está muy presente la regulación supraestatal derivada de organismos internacionales, como el Fondo Monetario Internacional y la Organización Mundial del Comercio, o regionales como la Unión Europea. La transformación y universalización de los mercados, la libre concurrencia y circulación y la necesidad de mejorar la competitividad de las industrias y los propios países en un mercado global han provocado la reducción de las exigencias y controles, así como la configuración de reglas de contratación pública más abiertas y universales. Las normas que regulaban la contratación administrativa han sufrido profundas modificaciones en cuanto a fines y valores, derivados de las instrucciones de dichos organismos y del Derecho comunitario, más preocupados por la transparencia y libre concurrencia que por la eficiencia de los recursos públicos.

Por otra parte, la decisión unilateral en la autotutela y la resolución de los conflictos en el ámbito administrativo o de la jurisdicción contencioso-administrativa van perdiendo su anterior significado y están siendo sustituidas por sistemas de transacción y arbitraje. Si la decisión de los procedimientos puede ser resultado de acuerdos, no debe sorprender que la convención alcance a otros supuestos y que se amplíen los espacios de resolución no jurisdiccional de conflictos. De este modo, tanto la función administrativa respecto a los conflictos como la posterior jurisdiccional van siendo postergadas en beneficio de formas negociales.

Los procesos de descentralización hacen surgir problemas de distribución de competencias entre las distintas Administraciones territoriales y sectoriales, sin que la cláusula de habilitación general que caracteriza a aquellas ayude a resolverlos. Las referencias legales a las competencias exclusivas son frecuentemente incorrectas por el predominio de las compartidas en lo material con exclusividad funcional. En todo caso, se impone la cooperación interadministrativa vertical y horizontal como uno de los valores emergentes del nuevo orden competencial. Tal cooperación alcanza a ámbitos orgánicos y territoriales intra y supraestatales en lo que se ha denominado la «Paradiplomacia» ${ }^{38}$.

\footnotetext{
38 F. Aldecon y M. Keating, Paradiplomacia: Las relaciones internacionales de las regiones, Madrid, 2000, pp. 17 y 22-23. I. D. DuсHАCEк, The Territorial Dimensions of Politics: Within, Among and Across Nations, Boulde y Londres, 1986, pp. 246-248, define la paradiplomacia glo-
} 


\section{LA GOBERNANZA EUROPEA}

Uno de los objetivos estratégicos fijados por el Parlamento Europeo en febrero de 2000 fue promover nuevas formas de gobernanza europea. El propósito lo expuso Romano PRODI: «Creo que tenemos que dejar de pensar en términos de poderes jerarquizados, separados por el principio de subsidiariedad y empezar a imaginar más bien la constitución de una red en la que los distintos niveles de gobernanza actúen conjuntamente en la elaboración, la proposición, la aplicación y el seguimiento de las políticas.[...] Es tiempo ya de darse cuenta de que Europa no está tan solo administrada por las instituciones europeas, sino también por las instituciones nacionales, regionales y locales y por la sociedad civil» ${ }^{39}$.

Los estudios se iniciaron con el «Programa de trabajo» titulado «Libro Blanco sobre la Gobernanza Europea. Profundizar en la democracia de la Unión Europea» ${ }^{40}$, que trazó una descripción de los distintos significados del término:

— «Gobernanza global»: utilizada por las Naciones Unidas señalando la necesidad de normas que sean objeto de un consenso y de una aplicación efectiva a escala planetaria, incluso en ausencia de gobierno mundial.

— «Buena gobernanza»: utilizada en las políticas de desarrollo, destaca que la transparencia, responsabilidad (obligación de rendir cuentas) y eficacia son condiciones indispensables para el éxito de las políticas públicas.

— «Gobernanza a varios niveles»: implica una articulación entre distintos niveles geográficos de agentes públicos independientes en torno a objetivos de interés común.

— «Gobernanza de empresas»: tiene por objeto garantizar la responsabilidad del poder de gestión frente a todas las partes interesadas ${ }^{41}$.

\footnotetext{
bal como los «contactos políticos con naciones distantes y que relacionan entre sí gobiernos no centrales no sólo con centros comerciales, industriales o culturales en otros continentes [...] sino también con las diversas ramas o agencias de los gobiernos nacionales extranjeros».

${ }^{39}$ R. PRodi, Dar forma a la nueva Europa, discurso en el Parlamento Europeo, 15 de febrero de 2000. La declaración número 23 del Tratado de Niza formuló la preconvocatoria de la «Conferencia intergubernamental CIG'2004», que servirá para la preparación de un nuevo Tratado, siguiendo la trayectoria de las conferencias de Maastricht (1991), Amsterdam (1997) y Niza (2000).
}

${ }^{40}$ Libro Blanco..., cit., p. 20.

${ }^{41}$ Libro Blanco..., cit., p. 3. 
El resumen del programa recogió un concepto de gobernanza común a las instituciones comunitarias y con repercusión en las de los Estados miembros: «El término gobernanza designa las normas, procesos y comportamientos que condicionan la calidad del ejercicio de los poderes europeos: responsabilidad, visibilidad y eficacia. Este enfoque es particularmente apropiado para la profundización en el modelo democrático europeo en general y en el papel desempeñado por la Comisión en particular, ya que da cuenta de situaciones caracterizadas por la multiplicidad de los centros de decisión a varios niveles geográficos, públicos y privados en la Unión. Destaca también la importancia de la legitimidad vinculada a la aceptabilidad de las normas, a la participación de los ciudadanos y a la consideración de la diversidad cultural, lingüística y territorial» ${ }^{42}$.

Los principios de la buena gobernanza, esenciales para que sea democrática, son los de apertura, participación, responsabilidad, eficacia y coherencia, que «no sólo son la base de la democracia y el Estado de Derecho en los Estados miembros, sino que pueden aplicarse a todos los niveles de gobierno: mundial, europeo, nacional, regional y local». Detalla el significado y alcance de tales conceptos, que son muy útiles a la hora de entender los principios comunitarios y su aplicación al gobierno y al Derecho:

- Apertura: «...trabajar de forma más abierta [...] desarrollar una comunicación más activa [...] utilizar un lenguaje accesible para el público en general [...] fomentar la confianza en unas instituciones de por sí complejas».

- Participación: «...amplia participación de los ciudadanos en todas y cada una de las fases del proceso, desde la concepción hasta la aplicación de las políticas [...] generar mayor confianza en los resultados finales y en las Instituciones $[\ldots] \gg{ }^{43}$.

- Responsabilidad: «...clarificar el papel de cada uno en los procesos legislativo y ejecutivo [...] explicar su acción y asumir la responsabilidad que le incumba [...] claridad y mayor responsabilización $[\ldots]$ en el desarrollo y aplicación de las políticas [...]».

\footnotetext{
${ }^{42}$ Libro Blanco..., cit., p. 20.

${ }^{43}$ D. GADBIN, «Organisation des compétences et stretégie d'intégration communautaire après le traité d'Union eropéenne», $R D P, 5,1995$, p. 1303, se planteó si la organización comunitaria debiera realizarse «en función de los modelos clásicos de organización de los poderes, o si prefigura nuevos modelos fundados en la articulación e interpenetración de múltiples redes, susceptibles de abrirse a la integración en el mundo de la economía y de la sociedad civil».
} 
- Eficacia: «...medidas eficaces y oportunas, y producir los resultados buscados sobre las bases de unos objetivos claros, de una evaluación de su futuro impacto y, en su caso, de la experiencia acumulada $[\ldots]$ aplicación proporcionada y decisiones [...] al nivel más adecuado».

- Coherencia: «las políticas desarrolladas y las acciones emprendida deben ser coherentes y fácilmente comprensibles» ${ }^{44}$.

El Libro Blanco propuso los siguientes cambios:

a) Una mayor participación de todos los actores sociales: a fin de hacer más transparente el sistema de funcionamiento, llegar hasta el ciudadano por la democracia regional y local, implicar a la sociedad civil ${ }^{45}$, una consulta más eficaz y transparente en la elaboración de las políticas y establecer vínculos con las redes.

b) Mejores políticas, mejores normativas y mejores resultados: dando confianza a las opiniones de los expertos, combinando los instrumentos para una mejor y más rápida normativa, simplificando el Derecho comunitario, con una mejor aplicación de las normas por medio de agencias reguladoras y a escala nacional. La mejora normativa pasa por la utilización del tipo de instrumento jurídico más adecuado.

Los objetivos serán desarrollados conforme a los principios de apertura, participación, responsabilidad, eficacia y coherencia, por una gobernanza de gran alcance, como es «integrar a los pueblos de Europa, respetando plenamente las distintas identidades nacionales». Los citados principios «no sólo deberían servir de referencia a la Unión para organizar su propio funcionamiento y para emprender las reformas en el marco del

\footnotetext{
${ }^{44}$ La Gobernanza..., cit., pp. 11 y 37.

${ }^{45}$ La Gobernanza..., cit., p. 16, destaca el papel de expresión, participación y movilización que le corresponde, con referencia expresa a las Organizaciones No Gubernamentales y a las organizaciones sindicales y patronales. En la nota 9, invoca alcance de la «sociedad civil» conforme al Dictamen del Comité Económico y Social sobre «El papel y la contribución de la sociedad civil organizada en la construcción europea», DO C329, 17.11.199, p. 30. Hace referencia expresa a la participación del Comité Económico y Social y del Comité de las Regiones. D. Wolton, Naissance de l'Europe démocratique, Flammarion, Paris, 1993, p. 231, alude a la despolitización de los ciudadanos de la sociedad individualista de masas: «...el ciudadano es hoy un gigante en materia de información y de consumo, y un enano en acción. Puede saberlo todo, o consumirlo todo, pero no puede actuar sobre una realidad, demasiado complicada, demasiado organizada». Propone la creación de estructuras intermedias, «en las que el ciudadano pueda insertarse y participar en la realidad de su entorno».
} 
actual Tratado, sino que deberían sentar las bases para el debate sobre el futuro de Europa» ${ }^{46}$. La voluntad política permitirá que el proceso de integración se desarrolle desde las propuestas de nueva gobernanza europea que haga posible:

a) Estructurar la relación de la Unión Europea con la sociedad civil: «Un código de conducta relativo al proceso de consulta identificará las respectivas responsabilidades y redundará en una mayor responsabilidad de todos los interlocutores. Promoverá asimismo el diálogo, y contribuirá a la apertura de la sociedad civil organizada».

b) Hacer un mayor uso de las capacidades y experiencia práctica de los agentes regionales y locales: «Esta tarea incumbe en primer lugar a las autoridades nacionales en el marco de sus disposiciones constitucionales y administrativas. La Unión debería asimismo hacer un mayor uso del potencial de flexibilidad existente para mejorar la aplicación de las políticas europeas sobre el terreno».

c) Reforzar la confianza pública en la utilización del conocimiento de los expertos por parte de los responsables políticos.

d) Sentar las bases de una más clara definición de los objetivos políticos de la Unión Eiropea y mejorar la eficacia de sus políticas «combinando la legislación formal con soluciones no legislativas y autorreguladoras con vistas a alcanzar más adecuadamente dichos objetivos».

e) Establecer las condiciones de creación de las agencias reguladoras europeas: «Estas agencias pueden reforzar la eficacia y visibilidad de la legislación comunitaria ante las empresas y el público en general, acercando las decisiones a los sectores afectados en algunos de los ámbitos más complejos y técnicos».

El Comité de las Regiones en su sesión de 13 y 14 de marzo de 2002 aprobó un dictamen en el que propuso una mejora en el Libro Blanco desde la aproximación a los ciudadanos a partir de los entes territoriales con las ideas de necesidad de información, necesidad de consulta regular, solicitud de colaboración en la elaboración de las políticas y mayor participación en la toma de decisiones, fomentando la cooperación vertical y horizontal: «La idea de una mejor articulación entre los niveles territoriales se ha puesto ampliamente en evidencia por el conjunto de los entes que

${ }^{46}$ La Gobernanza..., cit., pp. 37-40. 
ya han iniciado su propia integración en redes, para una cooperación vertical entre distintos niveles e intercambios horizontales entre entes del mismo nivel». Propuso como principios adecuados para una nueva gobernanza europea los de proximidad, subsidiariedad, proporcionalidad, coherencia, colaboración, consulta, participación, lealtad interinstitucional, apertura, transparencia, responsabilidad y democracia basada en la representación parlamentaria, pero también en el reconocimiento de la autonomía local, que ofrece a los ciudadanos libertades de participación en la solución de conflictos y derechos a disfrutar de los resultados obtenidos para todos.

En la «Convención sobre el futuro de Europa» del Consejo de Municipios y Regiones, de 16 de julio de 2002, se destacó cómo «en el mundo actual, complejo y cambiante, se hacen necesarias nuevas formas de gobiernos y de gobernanza para afrontar los retos a los que se enfrentan nuestros ciudadanos y nuestras sociedades. [...] es indispensable poner en marcha un sistema de gobernanza coherente e integrado, a escala europea y local. Si consideramos los problemas vinculados con la creación de empleo, la inserción social, la política urbana, el desarrollo rural, la inmigración o el medio ambiente, es evidente que las soluciones eficaces para cada uno de estos asuntos requiere un partenariado activo entre los diferentes niveles de gobierno». Lo reiteró en el punto 26: «Por lo tanto, en muchas políticas de la Unión como son el transporte, el empleo, la política rural, el medio ambiente, los asuntos sociales, etc., todas las autoridades locales y regionales juegan un papel importante dentro del marco de un sistema coherente e integrado de gobernanza. Este punto es vital a la hora de abordar los asuntos de subsidiariedad».

Además de los principios normativos y de una gobernanza comunes, en el orden jurídico europeo la primacía de la ética de los derechos humanos constituye una «clave de interpretación y de legitimación» del orden jurídico, que conduce necesariamente a una aproximación de los sistemas jurídicos nacionales al aplicar las mismas normas y jurisprudencia. A partir de aquellos se introduce la democratización de la Administración y la garantía de los derechos en el ámbito administrativo como los de participación en la decisión y gestión, concertación, transparencia, información, apertura de los procedimientos, mayor legitimación en los mismos, acciones públicas, etcétera ${ }^{47}$. Se invocan y aplican principios generales del

\footnotetext{
${ }^{47}$ El artículo 6 TUE invoca los principios de libertad, democracia, respeto de los derechos humanos y las libertades fundamentales y el Estado de Derecho, así como que las decisiones «deben tomarse de forma tan abierta como sea posible» (art. 1 TUE). P. AMSELEK, «L'évolution générale de la technique juridique dans les sociétés occidentales», RDP, 1982, pp. 292-293, «Ésta es hoy la
} 
Derecho que se constitucionalizan y otros relacionados con la buena conducta administrativa ${ }^{48}$, buena fe, la confianza legítima y hasta medidas cautelares consagradas por la jurisprudencia a través de la permeabilidad que, por ejemplo, se está produciendo desde prácticas jurídicas del common law.

El Libro Blanco ha recogido y formulado la doctrina de la gobernanza europea, con el efecto de su vigencia en el marco comunitario, de modo que se han establecido las bases comunes y el código de conducta para la dirección de la actividad de los poderes públicos estatales e infraestatales. Refleja el cambio en la elaboración y ejecución de las políticas públicas por la participación de la representación política y de los intereses afectados, que afecta a las concepción tradicional de la soberanía estatal y de las prerrogativas de los poderes públicos.

\section{LA GOBERNANZA LOCAL}

Como se ha expuesto, el nuevo escenario económico y la potenciación de los derechos y libertades, han desencadenado un proceso de acercamiento del poder a los espacios más próximos a la participación y a la decisión ciudadanas por la descentralización territorial y la creación de ámbitos político-administrativos dotados de autonomía, como los subestatales de carácter regional o autonómico y los locales, como refleja la Carta Europea de la Autonomía Local de 1985. El modelo descentralizado dentro del Estado unitario ha supuesto un desplazamiento del poder a los nuevos entes territoriales, la pérdida de los controles estatales propios del modelo centralista, la aparición de nuevas organizaciones administrativas, la transformación de la organización estatal y la configuración de un sistema jurídico más complejo. Las reglas de funcionamiento de la orga-

\footnotetext{
tarea primordial de los poderes públicos: ejercen una misión, por así decirlo, de negociación, de conciliación, de compromiso. Por ello, de técnica de dirección esencialmente heterónoma de conductas, el Derecho tiende a convertirse cada vez más en una técnica de cogestión de conductas que se inscribe en un diálogo permanente y complejo entre los gobernantes y los gobernados. En este sentido, la técnica actual destaca como aportación, más de cien años después, una afirmación que no fue escuchada de la famosa ley de Maine que se había relegado al museo de las ideas caducas, según la cual la técnica jurídica evolucionaría del estatuto al contrato». G. Del Vecchio, Philosophie du Droit, Dalloz, Paris, 1953, pp. 404 y ss. J. CARBonnIER, Sociologie juridique, Paris, PUF, 1978, pp. 354 y ss.

${ }^{48} \mathrm{El}$ derecho a la buena administración fue recogido en el artículo 41 de la Carta de los Derechos Fundamentales de la Unión Europea de Niza de diciembre de 2000 (DOCE C 364, 18.12-2000), Guía de las obligaciones de los funcionarios del Parlamento Europeo (DOCE C 97, 5-4-2000) y Código de conducta administrativa de los funcionarios de la Comisión Europea (DOCE L 308, 8-12-200). J. SöDERMAN, «El derecho fundamental a la buena administración», GJ, 214, 2001, pp. 8-14.
} 
nización administrativa basadas en la verticalidad y la jerarquía han sido sustituidas por la horizontalidad de los principios de solidaridad, lealtad institucional, cooperación, colaboración y coordinación, que han abierto un espacio de acuerdos y convenciones entre las Administraciones, reflejo del que se ha derivado de su democratización y de la participación ciudadanas.

En el último decenio del siglo xx se han constatado las transformaciones de la acción pública local, con un nuevo modo de gobierno de las ciudades que implica a todas las institucionales públicas y sociales. Se ha producido un incremento de la concentración urbana, que afecta a la población y a las actividades económicas, una progresiva urbanización de los espacios rurales, han aumentado el número y la actividad de las empresas de servicios públicos urbanos que actúan como concesionarias en la prestación de aquéllos, se ha configurado un sector público descentralizado con personalidad jurídica propia y formas jurídicas públicas y privadas, en muchos casos con presencia de otras personas, se ha desregulado y contractualizado el ejercicio de algunas competencias, se han generado nuevas relaciones entre el territorio y la localización de las actividades económicas y residenciales en nuevos núcleos, polos, polígonos, etc., con competencia entre distintos núcleos y espacios económicos para favorecer los asentamientos de actividades y servicios; se ha producido una apertura hacia el espacio supralocal y comunitario y se han potenciado las formas de participación y trabajo en redes. Todo ello ha contribuido a reducir la diferencia entre lo público y lo privado como espacios estancos de organización, régimen jurídico y actividad, así como al establecimiento de modos de participación, cooperación y coordinación para la definición del interés y la acción pública, que anteriormente eran exclusivas de los poderes públicos.

La complejidad del ámbito local lo hace más propicio al ejercicio de la gobernanza, porque es el espacio de mayor proximidad, institucional y geográfica, entre los ciudadanos y los poderes públicos, así como de ejercicio de la democracia real, en el que interactúan factores institucionales y no institucionales, formales e informales, de un modo accesible y sobre ámbitos competenciales directamente imbricados en la realidad social y en las necesidades individuales y colectivas. Es el marco de los problemas locales que, en cuanto puedan afectar a gran parte del resto de los espacios locales, manifiestan los problemas de dimensión regional y nacional.

El ámbito local ha quedado directamente afectado por las dos facetas de la gobernanza. Como modo de gobernar que posibilita la participación activa de los agentes sociales en la toma de decisiones de los poderes 
públicos, que configura nuevos espacios de poder ciudadano, que servirán mejor al interés público. Como un modo neoliberal de ampliar la presencia de los agentes económicos en la gestión pública. Una tercera valoración la considera como un medio para dar mayor legitimidad a las políticas públicas incorporando a la sociedad civil por el ejercicio de la democracia participativa.

\section{Concepto y características}

La gobernanza local ha sido definida como «el conjunto de reglas, estructuras y procesos formales e informales que determinan el modo por el que las personas y las organizaciones pueden influenciar las decisiones de terceros, que afectan a su bienestar en el ámbito local» ${ }^{49}$. El estilo de gobierno propio de la gobernanza se basa en la interacción, la cooperación y la participación, propias de las redes decisionales mixtas en las que participan los agentes públicos y los privados, por medio de las que se han denominado «políticas contractuales» ${ }^{50}$.

La gobernanza refleja la capacidad social para estructurarse por medio de instituciones capaces de gestionar con legitimidad, legalidad y eficacia las interdependencias. Son características de la gobernanza local:

a) Un escenario de muchos participantes en el que los problemas colectivos sólo pueden ser resueltos por los poderes públicos con la cooperación de otros protagonistas por medio de fórmulas de participación, colaboración, mediación, arbitraje y autorregulación que hacen más eficaz y legitima la acción pública.

b) Regulación por reglas formales (Constitución, leyes, reglamentos) e informales (costumbres, códigos de ética, etc.), que han sido elaboradas de modo participativo por los implicados en su posterior aplicación y evaluación, que la dotan de legalidad.

c) Utilización de las estructuras sociales, de las redes de cooperación y de los mecanismos de mercado y del management para la mayor eficacia de la gestión.

\footnotetext{
49 T. BovAIRD, E. LÖFfLER, «Passer des modèles d'excellence de fourniture de services locaux à l'établissement de repères pour une bonne gouvernance locale», RISA, 68, 1, 2002, p. 18.

50 J.-P. Gaudin (dir.), Politiques contractuelles, París, L'Harmattan, 1996. Dentro de estas opciones podemos situar el denominado «urbanismo concertado» o la iniciativa Leader de la U.E.
} 
d) Funcionamiento con lógicas de medios-fines, aportaciones-resultados, eficacia y eficiencia, y con otras más fundadas en los valores de la ética democrática, como la transparencia, la integridad, la honestidad, la responsabilidad, la confianza social, la igualdad, etc.

e) Toma de decisiones políticas por agentes políticos y en marcos políticos, no solamente por gestores y tecnócratas.

Se manifiesta como un sistema para articular las relaciones y tomas de decisión por medio de reglas y procedimientos que la configuran como una institución, con un contenido normativo en el que se reflejan los valores, los principios, las normas y los procedimientos formales e informales que los hacen operativos en las políticas públicas y en las actividades de todos los actores que participan en su formulación, aprobación, ejecución y control.

La gobernanza se organiza sobre las siguientes cinco situaciones o proposiciones complementarias:

a) Encuadra la actividad de un conjunto complejo y heterogéneo de instituciones y actores que no forman parte, necesariamente, del ámbito gubernamental o administrativo, con distintas legitimidades.

b) Los perfiles, límites y responsabilidades son menos claros en cuanto se refiere a la actividad y a la imputación de la actividad y de sus consecuencias.

c) Se establece una interdependencia entre las partes integradas en la acción colectiva interactiva, con incertidumbre sobre las consecuencias de las imprevisiones de la negociación y decisión.

d) Intervienen redes de protagonistas diferentes y autónomos, con escasa formalización y sin responsabilidad colectiva.

e) Se demuestra la posibilidad de actuar sin las autoridades estatales y supralocales, cuyo protagonismo se reduce a veces sólo a la aportación de medios de fomento y a dotar de las reglas necesarias para hacerlas efectivas y superar las dificultades ${ }^{51}$.

La gobernanza es también un método para analizar el funcionamiento de las instituciones, sus relaciones de coordinación, los procedimientos de decisión y control para establecer los más adecuados a las cambiantes realidades, de modo que permita prever y reaccionar ante los acontecimien-

${ }^{51}$ G. STOKER, «Cinq propositions pour une théorie de la gouvernance», RISS, 155, 1998, pp. 19-30. 
tos, así como tratarlos de modo sistémico. Todo ello con el fin de planificar, ejecutar, coordinar los modos de atender y satisfacer las demandas sociales, potenciar el desarrollo endógeno, capitalizar las potencialidades del exógeno, con la participación y movilización de los actores locales, privados y públicos, potenciando las actividades y organizaciones descentralizadas y desconcentradas, coordinadas por la gobernanza ${ }^{52}$.

Morata ha concretado los componentes clave de la gobernanza para el desarrollo sostenible en las dimensiones equivalentes a los requerimientos institucionales, que son plenamente aplicables en cuanto que la gobernanza debe ser sostenible:

a) Coordinación intergubernamental (integración vertical).

b) Coordinación entre las políticas sectoriales (integración horizontal).

c) Cambio en la cultura administrativa y en la calidad burocrática de la acción política.

d) Aplicación de una amplia e innovadora gama de instrumentos de políticas.

e) Cultura política participativa.

f) Cultura de la sostenibilidad.

g) Desarrollo del capital social ${ }^{53}$.

\section{Se fundamenta en las relaciones de cooperación}

La gobernanza en el ámbito local exige la descentralización, un marco legal adecuado y garantista de la autonomía, una suficiencia financiera para articular las competencias y prestar los servicios, una adecuada dotación de medios personales y técnicos. También precisa de un modelo de gestión eficiente por medio de la planificación, la cooperación y la coordinación, una organización participativa y no burocrática y la conversión de los poderes locales en agentes dinamizadores de la sociedad en todos los ámbitos propios de sus competencias y del progreso social.

\footnotetext{
${ }^{52}$ L. FAVREAU, «Du local au global: enjeux et défis des nouvelles initiatives de développement local et d'économie sociale», Économie et Solidarités, 29, 2, 1998, pp. 8-9.

53 F. Morata TIERra, «Sostenibilidad y gobernanza: el gran reto», resumen de un informe sobre «Los requerimientos institucionales del desarrollo sostenible», 2002, www.ecotropía.com.
} 
La gobernanza se asocia a la democracia en la administración, a la transparencia, a la participación, a la responsabilidad en la gestión y a la cooperación para el logro de los intereses comunes de los individuos, las organizaciones sociales y las instituciones. Sustituye los modos jerárquicos de los poderes públicos por los cooperativos y participativos, como efecto de la pluralidad de actores y modos de operar en las sociedades democráticas y abiertas. Este modo de actuar no desinstitucionaliza las decisiones ni deslegitima al orden institucional, sino que le dota de mayor legitimidad y apoyo a las acciones públicas al integrar a la sociedad en los procesos decisorios.

En todo caso, la gobernanza supone que la sociedad dispone de la capacidad y la voluntad de autogobierno, de organización y de los sistemas de representación necesarios para adaptarse a las nuevas necesidades y retos sociales, que le permiten configurar un nuevo modo de participar y distribuir las responsabilidades entre la sociedad y los poderes públicos. Este modo se caracteriza por establecer interrelaciones de cooperación y coordinación horizontal, variable y policéntrica —que no de jerarquía- entre los poderes públicos y la sociedad para hacer más eficaz y eficiente la acción pública, de contribución directa e indirecta de los ciudadanos y las organizaciones sociales y de creación de los instrumentos, reglamentaciones y procedimientos que establezcan las reglas del juego ${ }^{54}$. Además, la coparticipación en la toma de decisiones, en la ejecución y en la evaluación ofrece ventajas en un espacio complejo para la obtención de información, de recursos económico-financieros, de expertos y de competencias compartidas o concurrentes para ajustar las estrategias de las acciones ${ }^{55}$.

\section{Democracia y participación}

El estilo de gobierno basado en la interacción, la colaboración y la cooperación tiene como fundamento el principio de participación de los agentes públicos y privados en los procesos, que potencia su contenido democrático basado en la idea de democracia participativa, que refuerza la puramente representativa afectada por la apatía y el descrédito ${ }^{56}$. La par-

\footnotetext{
${ }^{54}$ B. Jessop, «The Rise of Governance and the Risk of Failure: The Case of Economic Development», International Social Science Journal, 155,1998, pp. 35-36; «The Regulation Approach, Governance and Post-Fordism: Alternative Perspectives on Economic and Political Change», Economy and Society, 24, 3, 1995, pp. 307-333.

55 P. Hamel, J.-G. Vaillancourt, «Partenariat public-privé et développement durable: l'exemple des politiques urbaines», Revue d'études canadiennes, 31, 1. 1996, pp. 48-59.

${ }^{56}$ H. C. Mancilla, «Las insuficiencias de la democracia contemporánea. Una crítica de las teorías de la transición», Política y sociedad, 34, 2000, p. 184, alude a la actitud antipolítica que se mani-
} 
ticipación, que es una de las más importantes manifestaciones de las libertades democráticas y de la equidad en las decisiones, exige una sociedad civil fuerte, estructurada, vertebrada, crítica y activa.

La gobernanza democrática parte de reconocer la identidad de los individuos y de los grupos en que se integran, su capacidad de acción política por medio de los grupos sociales y de los movimientos ciudadanos, la pluralidad de acciones y opciones políticas, sociales y culturales, y la existencia de un orden político-institucional capaz de incorporarlas y de adaptarse a los cambios ${ }^{57}$.

La democracia participativa, de la que son medios la gobernanza y el sistema de redes, concibe la democracia de modo integral y constituye un medio que activa todos los ámbitos sociales y políticos. No excluye los medios y procedimientos de participación institucional propios de la representativa, a la que complementa ampliándola a los espacios en que se adoptan decisiones de menor alcance político-institucional, pero que influyen directamente en la configuración del orden social y del espacio vital de los ciudadanos ${ }^{58}$. De tal modo que la democracia como proyecto político y la democratización como proceso social se encuentran en la gobernanza, que hace posible la toma de decisiones participadas y convierte a la participación en el ingrediente más importante del sistema.

Es en el ámbito local en el que la movilización social y, por tanto, la participación social son más viables en cuanto a las interacciones y a la presencia de y en las redes. El concepto de gobernanza territorial surgió

fiesta en la apatía de los ciudadanos y en el descrédito de la clase política: «Se trata de un hastío de la ciudadanía con respecto a los partidos, el Estado y la política en general; el ciudadano común y corriente pierde la poca confianza que tenía en la dimensión de la política y en sus actores principales. La consecuencia clara de todo esto [...] consiste en una clara pérdida de legitimidad del sistema de partidos y hasta del Estado, por una parte, y en la disminuida facultad de los partidos para poder captar y articular los anhelos y las exigencias de la población, por otra».

57 «La participación de la gente en las instituciones y sistemas que gobiernan sus vidas es un derecho humano básico, y también esencial para el realce del poder político a favor de los grupos desfavorecidos y para el desarrollo social y económico» (Informe FAO de 1981, invocado por FERN, «Forets ef fear», www.fern.org/ Library/Reports /humanrights.pdf, 2002, p. 9). Se ha comprobado la existencia de dificultades para incorporar algunos tipos de población pobre o marginal: $\mathrm{T}$. SouAmI, «Participer à la gouvernance?», Les Annales de la recherche urbaine, 80-81, 1998, pp. 163-171.

${ }^{58}$ La participación en la toma de decisiones sobre el planeamiento urbanístico plantea el obstáculo del contenido científico-técnico de sus documentos y determinaciones, que tienden a marginar al ciudadano del diálogo entre técnicos y autoridades por considerarlo un obstáculo o, al menos, una demora para las decisiones. R. ATKINSON, «Les aléas de la participation des habitants à la gouvernance urbaine en Europe», Les Annales de la recherche urbaine, 80-81, 1998, pp- 75-83. 
del análisis de las áreas metropolitanas como sistemas complejos locales, como modo para integrar los distintos elementos públicos y privados que las forman en la toma de decisiones para la acción pública territorial ${ }^{59}$.

A la participación se le empezó atribuyendo un carácter exclusivamente informativo sin capacidad de decisión, mientras que hoy se la califica como empowerment o apoderamiento, que atribuye un ámbito mayor de decisión incluso en las directrices estratégicas. La participación consiste en «acciones intencionales, legales o no, desarrolladas por individuos o grupos con el objeto de apoyar o cuestionar a cualquiera de los diferentes elementos que configuran el ámbito de lo político: toma de decisiones, autoridades y estructuras» ${ }^{60}$.

Se distinguen los siguientes tipos de participación ${ }^{61}$ :

a) Participación pasiva: por medio de representantes no electos, que contribuyen con recursos materiales y trabajo y reciben información sin poder de decisión.

b) Participación funcional: por medio de agencias externas que pueden participar en la toma de decisiones de escasa trascendencia, que no afecten a las estratégicas y más importantes.

c) Participación interactiva en las instituciones: en el análisis, desarrollo y control de la ejecución de los proyectos, con metodologías interdisciplinares y multi-propósito, con capacidad de decisión sobre las estructuras y prácticas.

d) Movilización y empowerment o apoderamiento: con capacidad de movilización para afectar a los sistemas, establecer contactos con otras instituciones para el asesoramiento y los recursos, que son controlados desde el espacio de participación ${ }^{62}$.

\footnotetext{
59 B. Jouve, «La gouvernance d'agglomérations en Europe: les leçons d'un échec» Pouvoirs locaux, 42, 1999, pp. 62-69. C. LEFĖVRE, «Gouvernements métropolitains et gouvernance dans les pays occidentaux», Politique et management public, 16, 2, 1998, pp. 35-60.

${ }^{60}$ J. M. SABucedo, Sicología política, Barcelona, 1997, p. 89. J. C. Alli Aranguren, «La evaluación ambiental como instrumento técnico-jurídico en las directivas 85/337, 97/11 y 20001/42», Ciudad y Territorio, XXXIV, 132, 2002, pp. 267-271.

${ }^{61}$ J. PRETTY, «Participatory Learning for Sustainable Agriculture», Word Development, 23, 8, 1995, pp. $1247-1263$.

62 J. M. Vogt, K. L. Murrell, Empowerment in Organizations, University Associates Inc., San Diego, 1990, p. 10: «El poder no es meramente un resultado, sino un proceso con sus raíces en el cambio de las estructuras social, económica y política de la sociedad. Es una manera de ser, una
} 
La gobernanza convierte a los ciudadanos y a sus organizaciones en actores sociales por medio de la participación. Para poder cumplir los fines perseguidos por la participación son precisos medios como la información, la consulta directa (encuestas, consultas y referéndum local), técnicas de presencia, toma de decisión, legitimación universal en defensa de la legalidad y del interés local, posibilidades inmediatas y rápidas de control de la actividad discrecional y reglada, así como de los ingresos y gastos públicos y un amplio sistema de garantías, asociacionismo local y formas populares de lucha contra las inmunidades y abusos del poder. Exige modificar los procesos de decisión para incorporar nuevas técnicas que permitan la participación en la toma de decisiones de trascendencia colectiva como la ordenación del territorio, la planificación urbana y cuanto afecta al desarrollo sostenible ${ }^{63}$. Constituyen medios de concertación y participación:

- La democratización de los procedimientos de planificación y consulta.

- La configuración de distritos y Consejos de barrio para participar en las decisiones de la ciudad, facilitar la comunicación con los ciudadanos, recibir consultas, hacerles participar en las decisiones y en su evaluación.

- Crear corporativos adjuntos de barrio o distrito con funciones delegadas para la gestión de las acciones en el área, con capacidad de decisiones sobre la mismas y de gestión de los recursos aplicables.

- Constituir Comisiones informativas abiertas a los representantes de zonas y de instituciones de participación y asociaciones de afectados.

- Presentación en los barrios de los proyectos que les afecten y de las propuestas presupuestarias.

- Favorecer los debates en los espacios cívicos y sociales sobre cuestiones municipales y, en particular, las relacionadas con los servicios sociales, los equipamientos, las infraestructuras, el urbanismo.

— Fomentar la creación de grupos de acción y participación municipal.

\footnotetext{
manera de pensar, no meramente una moda, táctica o un rápido apaño. El adquirir poder por las personas es un largo proceso de vida que requiere fundamentalmente cambios, y que sólo puede ser construido gradualmente. Cada paso deber ser construido sólidamente, comenzando por uno mismo [...] Una vez que lo propio ya está construido, el proceso puede continuar hacia las relaciones, grupos, organizaciones, naciones y sociedad como un todo».

${ }^{63}$ M. Pongy, «Gouvernance et citoyenneté. La différenciation du politque», en G. SAEZ, J.-P. LERESCHE, M. BASSAND, Gouvernance métropolitaine et transfrontalière. Action publique territoriale, París, L'Harmattan, 1997. M. AutES, «De la gestion de l'espace à la production du territoire, le résistible retour du politique», Pouvoirs locaux, 29, 1996, pp. 81-86.
} 


\section{La gobernanza y la creación de redes}

La gobernanza de la denominada network society recoge la idea de un modo descentralizado de gobernar en el que participan los ámbitos de gobierno supra e infraestatales y la sociedad. Constata la complementariedad funcional y la interacción entre los sujetos protagonistas de las políticas públicas en una sociedad estructuradas en sistemas de redes.

Las redes de acción política (policy networks) son estructuras de relación referidas al poder instituido y a sus relaciones con otros poderes y con los grupos de interés ${ }^{64}$. La gobernanza las concibe «como un mecanismo para movilizar recursos políticos en situaciones en las que estos recursos están muy dispersos entre los actores públicos y privados», así como formas de relación entre los grupos de interés y el Estado ${ }^{65}$. La interacción de los poderes públicos y de los agentes sociales contribuye a incrementar la interdependencia entre los poderes públicos y la sociedad en las decisiones y en su ejecución, que determina la creación y desarrollo del sistema de redes ${ }^{66}$. La utilización del paradigma de las redes contribuye en el proceso gubernamental al mejor análisis, definición e implementación de las políticas comunitarias, estatales, regionales y locales ${ }^{67}$, así como a articular las acciones de carácter vertical y horizontal ${ }^{68}$.

Las redes se han descrito «como una forma de interacción entre numerosos individuos y/u organizaciones. En relación con otras formas de interacción identificadas como el contrato/mercado y la jerarquía, las redes constituyen una forma intermedia que asocia de un modo estructurado

\footnotetext{
${ }^{64}$ E.-H. KLINJ, «Analysing and Managing Policy Processes Complex Networks: A Theoretical Examination of the Concept Policy Network and its Problems», Administration \& Society, 28, 1, 1996, pp. 90-119.

${ }^{65}$ T. A. BörzEL, «What's so Special about Policy Networks?: An Exploration of the Concept and its Usefulness in Studding European Governance», European Integration Online Papers (EIOP), 1997, 1, 016; «Policy Networks: a New Paradigm for European Governance?», EUI working paper RSC, 97/19, Badia Fiesolana, San Domenico; European University Institute Robert Schuman Centre, 1997.

${ }^{66}$ F. Morata-K. Hanf, Gestión pública y redes de políticas públicas: La gobernación del medio ambiente en Cataluña, Barcelona, 2000.

${ }^{67}$ A. Cole-P. John, «Les réseaux locaux de politiques publiques en France et en Grande Bretagne», en P. Le Galès-M. Thatcher, Les réseaux de politique publique. Débat autour des policy networks, París, 1995, p. 213, «la red local es en primer lugar una metáfora, un mecanismo para clasificar los actores claves locales por sector, por ciudad, por país [...]. La red local de la política pública describe las relaciones complejas que existen entre los protagonistas en diferentes sectores que se interrelacionan».
}

${ }^{68}$ A. FERNÁNDEZ, «Las políticas...», cit., pp. 476-478. 
pero flexible a partes independientes, cada una de las cuales controla una parte de los recursos y las competencias necesarias a todos para conseguir objetivos comunes» ${ }^{69}$.

Las redes se crean y desarrollan desde el convencimiento de que los problemas, su tratamiento y soluciones no suelen coincidir con la división competencial o con las demarcaciones en que actúan las instituciones públicas. Sirven para plantear, decidir e implementar las políticas públicas por medio de actividades gubernamentales concretas a partir de un orden normativo que las legitima y posibilita. Constituyen un proceso complejo político-institucional a fin de establecer un espacio de estudio, planificación y acción entre las instituciones y la sociedad para adoptar las decisiones y acciones referidas a conflictos y necesidades sociales, con mayor o menor obligatoriedad según sea la decisión de los sujetos que las comprometen y protagonizan ${ }^{70}$.

\section{CONCLUSIÓN}

La gobernanza trata de integrar a los ciudadanos en los procesos de decisión sobre las políticas públicas, a partir de realidades complejas por la diversificación y autonomía, democratización y compromiso cívico. Exige concebir e implantar una estrategia de cambio para hacer posible una mayor legitimidad, confianza y eficacia, que modifica las estructuras organizativas, representativas y de toma de decisiones en la complejidad de los nuevos ámbitos y las nuevas relaciones. Reconoce la multiplicidad de actores y la necesidad de hacerlos partícipes en los procesos de decisión, ejecución y control, por medio de la cooperación, la concertación y la participación. Es medio para renovar la democracia local y para dar mayor legitimidad a la acción pública. Produce redes de cooperación que son aportaciones sociales para satisfacer necesidades colectivas.

\footnotetext{
${ }^{69}$ UnIÓN EuRoPEA, Grupo 4b, Informe del grupo de trabajo «Gobernanza en una Europa en red», para el «Libro Blanco» sobre Gobernanza.

${ }^{70}$ F. Morata, «Políticas públicas y relaciones intergubernamentales», Documentación Administrativa, 224-225, 1990-1991, pp. 156-158.
} 